\title{
Disability and Identity Transformation in Selma Dabbagh's Out of It
} https://doi.org/10.33806/ijaes2000.21.2.3

\author{
Laura Bashiti \\ The World Islamic Sciences and Education University, Jordan
}

\author{
Nedal Al-Mousa \\ Arab Open University, Jordan
}

\begin{abstract}
This paper examines the significance of disability in Arab British novelist Selma Dabbagh's Out of It (2011). It underscores how disability engenders an identity transformation that Sabri Mujahed undergoes in the novel. The study highlights how disability triggers resistance strategies to the oppressive socio-political norms and occupying powers. The paper also draws attention to the psychological and socio-cultural impacts of disability on the life of Sabri Mujahed. Sabri turns his skills toward a great mission of writing the history of Palestinian resistance and exposing aggressive Israeli policies. The process of writing itself has a therapeutic effect that helps Sabri overcome his disability and channel his mental powers to a greater cause. Taking into consideration disability studies' tendency to provide a fresh approach to understand a disabled character's inner world, this paper employs disability studies as a theoretical and critical framework in light of which the novel is analyzed. The paper also foregrounds the sociopolitical, cultural and historical conditions and circumstances that Palestinians in Gaza experience and undergo. In this context, continuous Israeli military attacks, a stifling blockade and internal factional conflicts are some of the challenges that people in Gaza, including disabled Sabri, have to cope with on daily basis.
\end{abstract}

Keywords: Arabic literature in diaspora, disability in literature resistance, identity transformation, socio-cultural impact

\section{Introduction}

Sitting on his wheelchair behind a desk in an apartment in war-ravaged Gaza, Sabri Mujahed, one of the main characters in Arab British novelist Selma Dabbagh's debut novel Out of It (2011), informs his disgruntled younger brother Rashid that he is currently writing a book that documents recurrent Israeli attacks on Palestinians. He examines milestones in Palestinian resistance history and traces the origins of Palestinian factional conflicts. Sabri maintains: "My thesis being that the Occupation, the closure, the siege have made amputees of all of us, crawling around in the mud. Legless in Gaza. The lot of us" (Dabbagh2011: 107). Sabri, who dedicates himself wholeheartedly to writing the Palestinian history, states clearly how the Israeli occupation of Palestine and the siege on Gaza have contributed to creating physical and psychological disabilities among the Palestinians. His words epitomize the crippling situation under which Palestinians are living. Palestinians are prone to systematic acts of disablement, displacement and intended deformation of their national culture. Under the Israeli occupation, a 
great number of disabilities are produced and reproduced daily by an aggressive apartheid system. Since Sabri resides in Gaza, he focuses on the horrible situation under which Palestinians live in the tiny strip. Seen from Sabri's perspective, persons with disabilities in Gaza are an integral part of the Palestinian community, forming a diverse segment that makes important contributions in a wide range of fields.

Taking into account Sabri's words and the socio-political, cultural and historical circumstances that Palestinians, particularly those who live in Gaza, have been experiencing since 2007, this paper investigates the process of identity transformation that Sabri undergoes in Dabbagh's Out of It. It investigates how disability plays a pivotal role in shifting Sabri's attitudes, social communications and life perspectives. Set between Gaza, London and Arab Gulf states, the novel tells the story of three Palestinians whose lives exemplify the long-lasting Palestinian-Israeli conflict. The action revolves mainly around the Palestinian activist Sabri Mujahed who, after losing his family and his legs in an Israeli bombing, dedicates his life to documenting the history of Palestine, precisely the continuous Israeli attacks on the Gaza Strip. Out of It is a powerful spatial text that offers a nuanced insight into the intricate life of a person with a physical disability. The novel reveals the impact of the element of space on the formation of the hero's psyche. That is insofar as space is associated with specific personal experiences and memories which play a major role in the shaping of the individual's selfhood.

Sabri refuses to be silenced and chooses to speak back to the oppressor/occupier. From his marginal/liminal space, Sabri utilizes his voice to regain the narrative agency back. Sabri along with many Palestinians defy the occupier by refusing to be silenced. Dabbagh's protagonist manifests varying degrees of "mobility, political awareness and commitment" when he "challenge[s] hegemonic constructions" of the Israeli system (Moore 2015:3). Confined to his room, Sabri turns his skills toward a great mission of writing the history of the Palestinian resistance and exposing aggressive and atrocious Israeli acts and policies. In other words, Sabri is involved in "non-violent resistance to the Israeli occupation" (Dabbagh 2011: 45). Thus, the protagonist's body is the site over which discourses on identity, disability and nationalism converge. Through a close reading of Dabbagh's novel, this study shows how disability problematizes notions of identity construction, normality and resistance. In Out of It, Dabbagh advertently creates a character that challenges the "supercrip" narratives, which are either based on concepts of "heroism", the "extraordinary", and the disabled body with super powers (Schalk 2016: 71) or stereotypical images that focus on incomplete versions of humanity.

In the introduction to Disability Studies Reader (2013), Lennard Davis defines the normal as "constituting, conforming to, not deviating or different from, the common type or standard, regular, usual" (2013: 15). His definition enhances the basic understanding of disability and highlights the starting point from which disability theory launches its schemes. In this sense, disability is a subversion and deviation from the normal body. Categorizing citizens into 
"standard" and "nonstandard sub-populations", creates the concepts of disability and the disabled body (Davis 2013: 17). Thus, disability theories rise to proclaim the right of people with disabilities to be treated equally and fairly. Disability studies forms a critical response to the cultural assumptions that all people should be healthy, independent and included within the standard criteria. It opens up new horizons for reading literary texts. More specifically, disability studies provides a fresh approach to understand a disabled character's inner world, a world that is traditionally inaccessible via other critical and analytical approaches. Dabbagh's novel dramatizes the traumatic experiences of the disabled character who struggles to define his identity in the light of emotional and mental state of perplexity. The novel depicts the positive impact of disability on the private life of the individual and shows the significant role that a physical disability plays in his identity change.

\section{Disability studies, literary representations and socio-political contexts}

In the late twentieth century, many social and political movements have endeavored to redress the social inequality that people with disabilities had been experiencing for a long time. By organizing a series of campaigns, organizations such as Union of Physically Impaired Against Segregations (UPIAS) managed to force governments to pass legislation, like the Disability Discrimination Act (DAD), in a bid to rectify social injustice and prejudice against disabled people and centralize the issue of disability within the public sphere (Goodley 2010: 31). Traditionally, disability was placed within medical perceptions as it was recognized as a pathological problem. However, this essentialist outlook was later reversed to a socio-political and cultural one. Several theorists from different academic disciplines reject the notion of delineating disability as a physical or cognitive impairment "that is necessarily in need of cure, rehabilitation or concealment" (Hall 2015: 21). In fact, the process of locating disability in the individual body aside from the surrounding environment maintains, and even augments, the disabling status quo.

Triggered by social activism, disability studies established itself in the late 1980s as an independent scholarly field (Hall 2015:19). Disability studies is the theory, research, scholarly discipline and practice rising to reverse the conventional view of disability as a personal, individual matter, presenting it instead as a social construct. While one may "identify people as having physical, sensory, cognitive or mental health impairments," Goodley argues that "disability studies place the problems of disability in society itself" (2010: xi). In this sense, a disability stems from "society's failure to remove the wide-ranging social, economic, and environmental barriers" (Barnes and Mercer 2001:515) which cause and underscore the social exclusion of people with disabilities and deny them their legislative rights. Disability studies have also been influenced by other recent cultural and social movements like postmodernism, postcolonialism, women and race studies. It has emerged as a revolutionary critical movement that responds to the hegemonic ideology and preconceived notions of the disabled body. 
The history of disability studies is best conceived in terms of overlapping waves that stabilize, conceptualize and problematize the basic foundations of the discipline. One of the earliest texts of disability studies is Paul Hunt's Stigma: The Experience of Disability (1966). In his work, Hunt presents the issue of disability as it exists not only in the impairment, but also in "our relationship with "normal people"" (2015: 146). Hunt's statement lays down the foundations of disability theory and research, where the social, cultural and political environment is what constitute a barrier in front of individuals with different forms of impairment. Different models of disability studies lead to variable identifications with disability, its position and social structure. The most apparent and groundbreaking models are the social model, minority-identity model and the cultural, intersectional or multi-disciplinary model. The traditional model of disability classifies disability as a defect, a pathology that needs medical treatment. Medicalization or what is sometimes called the "individual model" treats people with disabilities in hospital, institutions and rehabilitation systems (Hall 2015: 166). As a matter of fact, the medical model forms the exact polar opposite of the social one which originally shaped the foundational standpoint of the field of disability.

The social model defines disability as a condition created out of the disabling environment, practices and forms of discriminations against persons with impairment. In doing so, scholars of the social model base their discussion on a key distinction between "impairment" and "disability". Impairment is "lacking part of or all of a limb, or having a defective limb organism or mechanism of the body" (Goodley 2010: 8). As for "disability", it is understood as "the disadvantage, restriction of activity or limitation of opportunities caused by the social organizations, institutions and regulations which take no account of people who have physical impairments and thus exclude them from mainstream social activities" (Barnes and Mercer 2001:11). A number of disability movements have called for the emergence of a "minority identity" that unites people with various impairments as they experience similar forms of oppression and marginalization by the "abled-bodies" (Gibson 2006: 89). However, the idea of a minority identity that stipulates people with disability to be classified into one category reinforces the stereotypical images previously imposed on them by the dominant structure. As Gibson emphasizes, enforcing a disability identity that works to ground an opposition or "binaries" between the disabled/abled, the self/other reinforces the ablest notions of independent individuality which disability rights movements originally rise to thwart (2006: 189).

When placed in global contexts, views on disability vary according to the cultural context in which disability is explored. Herein, Michael Davidson (2008) suggests that the models of disability formed in Western cultures are "inappropriate" in other cultures of the globe. He stresses the importance of a "historicized" and culturally specific modeling of disability (2008: 172). Davidson's words may remind one of Stuart Hall's description of "cultural identity" as a matter of "becoming" as well as of "being". For Hall, "cultural identity" is not something which already exists, transcending place, time, history 
and culture; a cultural identity undergoes constant transformation (Hall 1994: 224225). By the same token, Alice Hall (2012) argues that a disabled person's identity is constructed within the particularity of history: "It is not an essence but a positioning which places disability against and outside the falsity of universality notion" (2012: 226). In this sense, the flexible approach to disability assists scholars and theorists to understand people with disability and identify with them as more than just disabled people. The way Stuart Hall defines identity challenges the static representations of disability identity as one-faced, universal and stereotypical. Since identity itself is in constant flux, always fluid and shifting, identities of disabled persons are rather fluid according to different settings, places, cultures and positions.

Disability studies also highlight the importance of cultural contexts as a main factor to define disability with regards to the global cultures of the world. Aside from the Eurocentric concepts and ideologies which form the basis of the field, postcolonial disability studies place themselves as a replacement to the essentialist concepts of individuality, normality and medical discourses. These concepts which have long dominated the Euro-American societies, according to many activists and global disability theorists, are insufficient or inconclusive and even clash with the diversity of disabilities in different cultures. Correspondingly, disability studies have to accommodate its methodologies to colonial/postcolonial contexts. (Barker and Murray 2010) identify the "situated analysis", cultural "difference", "environments of disability" and the representational models as appropriate approaches within colonial/postcolonial nations (220). To illustrate, in Dabbagh's novel, Sabri Mujahed experiences disability in war-torn Gaza. Recurrent Israeli offensives on Gaza have killed thousands and left thousands of others impaired with no medical care because of the strangling Israeli siege imposed on the tiny strip since 2007. Besides, Sabri's disability is brought about by an Israeli bombing in an attempted assassination. Moreover, just like most people living under Israeli occupation in Palestine, Sabri suffers from disabling conditions including physical restrictions on travel abroad. Thus, it is apt to examine Dabbagh's representation of Sabri's disability within the context of colonial/postcolonial conditions and circumstances.

Since people with disabilities and postcolonial societies have experienced various forms of marginalization, cultural exclusions and discrimination, it is unsurprising that postcolonial theory has substantially influenced disability studies. In Alice Hall's perspective, "postcolonial theory informs the critical language and framework" of disability studies with regards to the issue of representing the other, or in other words, speaking for the others (2015:48). Seen from this perspective, disability theorists rely heavily on their postcolonial counterparts in modeling the critical analysis of disability. The intersection between both disciplines shows how postcolonial theory is essential to "globalize" the field of disability, to challenge "the universal disability identity", and to revisit the universal dominant models of disability, in favor of a multidisciplinary model (Hall 2015: 50). Yet, Barker and Murray warn that because disability studies "problematically transports theories and methodologies developed within 
the Western academy to other global locations" (Barker2010:20), little notice is given to the intricate local formations of people with disability forms worldwide. Thus, the proposition to extend disability studies beyond the Westernized models necessitates the examination of disabilities within diverse cultural frameworks.

Alice Hall's two foundational books, Literature and Disability (2015) and Disability and Modern Fiction (2012) investigate the representation of disability in literary texts. Hall is mainly interested in exploring the aesthetic, ethical and emotional importance of physical disability in literary works. Hall describes the role of literature in understanding a disability as a "productive critical reading" which has the potential to present some "complex" and "non-normative" characterization of disability (2012: 34). Overall, literary narratives invite readers, mainly non-disabled people, to look, feel and imagine the quotidian experiences of people with physical disabilities. Literature offers a suitable "location" where "imaginative identification" could be possible (Hall 2015: 35). In Narrative Prosthesis: Disability and the Dependencies of Discourse (2014), David T. Mitchell and Sharon L. Snyder argue how a powerful "mediator" the narrative can be between two worlds (2014: 5). Seen from this perspective, disability studies open up new horizons for reading literary texts. Studies on disability within the postcolonial context have recently gained viable grounds. Clare Barker's "Disability and the Postcolonial Novel" (2016) and Ato Quayson's Aesthetic Nervousness: Disability and the Crisis of Representation (2012) investigate representations of disability in postcolonial literary texts in relation to the setting, culture, and individuals who belong to that culture. Abir Hamdar's The Female Suffering Body: Illness and Disability in Modern Arabic Literature (2014) explores female physical illness and disability in contemporary Arabic literature, including the works of prominent Palestinian writer Ghassan Kanafani. Using disability studies as a theoretical and critical frame to investigate literary texts adds new dimensions to the conventionally static image of people with disabilities.

In postcolonial literary works, disability provides vivid metaphors and images that form the basic elements in postcolonial fiction. In this context, the body politics paves the way to understand, analyze and encapsulate the oppressive power structures of colonialism, imperialism and globalization in the postcolonial world. Dabbagh explains in correspondence with the researchers that her "desire" to include a disabled character in her novel is to attend to the "high level of disability in Palestine, particularly in Gaza". This in turn enables her to present such a major issue while addressing the overall picture of Palestinian sufferings. Motivated by the "number of attacks on that small strip of land", Dabbagh decides to place the disabled character Sabri as the main character in the novel, a type of character that represents the old generation of resistance. Sabri's body is metonymic for Gaza under siege. In this sense, the paralyzed body of Sabri embodies the ceaseless procedures to dysfunctionalize the national body of Gaza. 


\section{Disability, Resistance and Identity Change in Dabbagh's Out of It}

In Out of It, Dabbagh attempts to challenge the negative static images of people with disabilities by presenting the unique experiences of Sabri Mujahed. The novel traces wheelchair-bound Sabri's identity transformation as he becomes an inspirational figure and a role model for others. In this paper, Out of It is read within the framework of a cultural model of disability that highlights how the Israeli occupation of Palestine, the stifling siege imposed on the Gaza Strip since 2007 and the constant Israeli military assaults create a mass physical disability. The model used here is culturally sensitive and it expresses different key concepts of disability and disabling conditions. Ilan Pappé (2015) brilliantly explains the situation in Gaza revealing how Israel deals with this situation:

Ever since 1994, and even more so when Ariel Sharon came to power as prime minister in the early 2000s, the strategy there has been to ghettoize Gaza and somehow hope that the people there 1.8 million of today - would be dropped into eternal oblivion. (2015: 150)

In other words, after the Oslo Peace Accords with the Palestinians in 1993, Israel has endeavored to completely isolate Gaza from the West Bank in a way that obstructs the creation of a prospective Palestinian state. To do so, Israel waged a number of wars on Gaza since the 2006 Palestinian elections that brought Hamas to power.

The first major assault, codenamed Operation Cast Lead, took place between December 2008 and January 2009; the second major offensive, codenamed Operation Pillar of Defense was in October 2012, while in July 2014, Israel launched Operation Protective Edge. These attacks killed thousands of Palestinians and left thousands of others injured and maimed, some with permanent impairment. Operation Protective Edge almost devastated Gaza's infrastructure and Israeli warplanes unashamedly targeted care centers for disabled people. Al Jazeera reported on its website that in one attack, Israeli jet fighters raided a rehabilitation center for the disabled in Jabaliya, killing three disabled people and a nurse. The second invasion targeted the Society of Physically Handicapped People's buildings in the Zeitoun neighbourhood in the southern Gaza Strip, leaving one hundred and forty disabled children without a school. These attacks were launched alongside a siege imposed on Gaza since 2007. Chomsky's reflections on this issue are revealing:

With their vaunted technical efficiency, Israeli experts determined exactly how many calories a day Gazans needed for bare survival, while also depriving them of medicines, construction materials, or other means of decent life. Israeli military forces confined them by land, sea, and air to what British Prime Minister David Cameron accurately described as a prison camp. The Israeli withdrawal left Israel in total control of Gaza, hence, the occupying power under international law. (2115: 158)

As Chomsky clearly shows, Israel's siege on Gaza makes the lives of around 1.8 million people quite hard. Eye-witness accounts by Norwegian trauma 
surgeon Mads Gilbert and human rights lawyer Raji Sourani demonstrate the deteriorating health conditions that people in Gaza have been experiencing since 2007. All these socio-political circumstances and cultural questions need to be taken into consideration when evaluating Dabbagh's representation of wheelchairbound Sabri's identity transformation.

As a matter of fact, the Israeli occupation of Palestine is the cause for Sabri's and his people's disability literally and figuratively. In this sense, narrating the main character's disability helps in articulating the Palestinian struggle under occupation and siege. Sabri dedicates himself wholeheartedly to documenting the history of Palestine, precisely the brutal attacks on Gaza and the Intifadas (Palestinian uprisings). Despite the fact that the novel is set in multiple locations, the central place is Gaza. Moore (2015) attributes the importance of Dabbagh's novel to the fact that "it foregrounds an ongoing Palestinian history of life under occupation, siege and apartheid" (2015: 325). Specifically, Moore argues that Dabbagh's work is essential because it vividly presents Gaza, which among other areas, remains "underrepresented in the literary and theoretical domain" (ibid: 325). The way Dabbagh portrays her characters defies in so many ways the stereotypical image of a unified Palestinian character, which adds to her vivid and colorful new presentations of the "old realities" (326).

Journalistic reports and news coverage of Israel's most recent major military assault on Gaza in 2014 document some of the brutal and inhumane acts of genocides, mass killings, and militant attacks that Israel has committed. Numerous reports carried out by international human rights organizations such as the United Nations Human Rights Council (UNHRC), the World Health Organization (WHO) and Handicapped International show the intended and systematic devastation of Palestinian lands, populace and infrastructure by Israeli armed forces in the successive assaults on Gaza. UNHRC's commission of inquiry declared that the war on Gaza in 2014 caused the deaths of 2,251 Palestinian civilians, among them 551 children (UNHRC Para. 20). Also, around 11,231 Palestinians, including 3,540 women and 3,436 children, were injured, of whom 10 percent suffered permanent disability as a result (UNHRC Para. 20). In addition, Israel has been targeting residential buildings, hospitals and care centers. As a result, countless people were injured and impaired severely, with massive disabilities inflicted on a great proportion of the population of the Gaza Strip.

Given that colonialism has "a history of mass disablement" (Barker and Murray 2010: 230), the Israeli occupation of Palestine is no exception and can be certainly labelled as a systematic disabling process. More specifically, Gaza, under siege since 2007, struggles against the continuous attempts of destruction, devastation and crippling processes. The continuous attacks of the Israeli military result in huge numbers of deaths, injuries and physical impairments among the people of Gaza. These circumstances necessitate understanding disability in Gaza within the context of a national crisis rather than isolated individual cases. In other words, taking into consideration the particularity of the Palestinian situation, disability is not conceived in a normal sense, where it is the result of a casual 
accident. Rather, it is conceived as one of the gravest impacts of Israeli aggressive occupying power, assaults and continuous violations of civilians.

In Out of It, Sabri experiences two forms of suffering: physical and emotional/psychological. The physical suffering is manifested mainly in his constant feeling of pain and inability to move and it results in Sabri's confinement in "a wheelchair with sores across his buttocks" (Dabbagh 2011: 32). Sabri becomes a "body" that his mother had to "lift in and out of bed" (ibid: 32). Living in besieged Gaza constitutes a double challenge for people with disabilities. To overcome this problem, Sabri's mother switches apartments with their neighbors who live on the ground floor, so that Sabri "can wheel himself out" (ibid: 24). Rashid, Sabri's younger brother believes that by staying so confined, Sabri will eventually be "rotting up" in his room (ibid: 24). The Israeli blockade on material goods into Gaza leads to "severe shortages of medical supplies"( ibid: 26) . As a matter of fact, inability to move due to the lack of artificial legs supplies in medical centers in the Gaza Strip contributes heavily to Sabri's isolation, depression and, at certain moments, despair.

Physical suffering is inextricably-connected to emotional and psychological pains. Despite continuous efforts to conceal his emotions, Sabri is always stressed, restless and easily agitated. As "Lana [his wife] was everywhere", his past with her "kept coming back in random flashes of memory" (ibid: 41, emphasis added). Her ghost approaches him in the morning and even dwells in his own crippled body. Keeping Lana's shirt in a plastic bag so that it will not lose its scent is one of Sabri's tactics of coping with his emotional and psychological agonies. The traumatic effects of the accident keep recurring as flashbacks. As a way to expresses his disgruntlement and disappointment for losing his legs, from time to time, Sabri "rolls his wheels on" the signed photograph of the former Palestinian leader that was given to him by the delegation that visited him in the hospital after the assassination attempt. In doing so, he expresses his resentment to the ruling party which after the accident treated him as an amputee who is incapable of participating in political activism.

Beside experiencing the loss of his family and legs, Sabri experiences another form of psychological trauma; being the object of the gaze of others. The shame of being looked at does not only disturb Sabri, but it also augments his sense of isolation and confinement. For instance, when Rashid and his friend Khalil pay Sabri a visit, the two men "hesitated" to come closer as Sabri was sitting with his naked amputated legs "thrust out at them" (ibid: 104). Even with his own family, Sabri prefers to be seen "behind a desk or on the other side of the kitchen table" so that only his arms are "visible and everyone could pretend that the chair was not there and that his legs were" (ibid: 104). Under of the gaze of others, Sabri could sense the humiliation of being looked at, pinned down and objectified. Sabri explains that he covers his leg so that no one, including his family, sees him with deformed legs.

The hegemonizing gaze perpetuated by the Israeli apartheid system is what disturbs Sabri most. In a speech delivered at a critical time during the war on Gaza, Sabri listens to the Israeli Prime Minister pejoratively describing 
Palestinians as "beasts walking on two legs" (ibid: 107). For Sabri this statement is so annoying and depreciating since it touches him directly and makes him feel doubly marginalized and humiliated along with other Palestinians with disabilities who make up a significant group of Gaza's population. Thus, within the context of the blockade imposed on Gaza by the Israelis, the disabled body of Sabri is an embodiment of Palestine's state under occupation and siege. As Sabri distances himself from others, he finds a comfortable place among his books. He resorts to writing as a tool for communicating his woes and anguishes as well as building rapports with people around him. In fact, it is in chronicling Israeli attacks on Palestinians and documenting the contemporary history of the nation that Sabri transcends his disability and liberates himself from confinement.

That Sabri does not capitulate to his disability speaks volumes for Palestinian people's resilience and fortitude. The theme of resilience gains impetus through dismantling the boundaries between literature and history. Similar views are held by Yousef Awad in a context related to Aboulela's novel The Kindness of the Enemy. That is in the article published in International Journal of Arabic-English Studies.Despite the unrelenting attempts to devastate the Palestinian people's free will and the crippling conditions under which they live, especially in Gaza, their unyielding spirits defy all obstacles. Sabri, like other fellow Palestinians, resists and survives the impacts of disabling conditions. In the Palestinian context that the novel portrays, Sabri's disability, to use Baker's words, is "recognized as a part of the community life rather than as an individual's personal stigma" (2015: 108). Disability here is a catalyst for empowerment. Dabbagh turns his disability into a conduit for identity transformation, communal solidarity and national sacrifice. In other words, in Dabbagh's novel, disability is a badge of honor that Sabri and fellow Palestinians carry on their chests since their disabilities are caused by the enemy. While Sabri's disability reflects the Palestinian people's state of paralysis under Israeli occupation, Sabri's identity transformation and his desire to overcome his disability represent the nation's refusal to be subjugated and humiliated. As the narrative frequently demonstrates, Sabri is at the heart of this struggle. He relishes "this history of uprising that he had to live through" (Dabbagh 2011:38). Sabri overcomes his personal tragedy to address a national obligation towards his country.

Sabri's identity transformation is clear in two areas. On the national level, Sabri decides to dedicate himself wholeheartedly to documenting the history of Palestine and the present struggle under Israeli occupation. On the personal level, Sabri becomes a spiritual mentor, a care giver and even a role model whose influence affects all other characters. He carries upon his shoulders the responsibility of his family, adopts his neighbor's child and grants his apartment to neighboring refugees living in tents. In doing so, Sabri overcomes his disability and becomes the embodiment of the father figure of the Palestinian struggle. He indeed becomes a hero who champions his nation's cause and carries its concerns. The national and personal levels often intersect and overlap and, eventually, Sabri emerges as a key pillar in the Palestinian socio-political structure. 
In his discussion of identity formation, Stuart Hall explains that cultural identity is not merely rooted and fixed to human history, but it is also a production, a revisit of the past (1994: 235). Hall argues that an "identity [is] grounded [. . .] in the re-telling of the past" (ibid: 224). In the case of disabled people, identity is formed and continuously constructed after the transformational process of the two stages: the denial stage and the acceptance/adaptation stage. In her article, "Disability and Identity", Margaret Wangui Murugami argues that disability plays a pivotal role in identity formation:

Challenging social systems, in which persons with disabilities are subordinated through relations that are contradictory to their own views of self, helps persons with disabilities to create self-identities that are far removed from biomedical models that present disability as tragedy (2009: 10).

Thus, the identity of a disabled person is formulated out of a conscious choice that is various, diverse and encompassing. In this sense, disability is enabling; it enables the individual to form a self-identification that is difficult to categorize or even label by the limitations of some disability politics and medical frameworks. In this way, disability enables individuals to construct their identities through the interactive relationships with their surroundings.

Sabri's socio-political role shifts from field activism to intellectual and academic activism. This type of resistance is manifested in writing, researching and collecting diverse materials about Palestine, before and during occupation. Sabri undertakes the mission of writing the history of the Palestinian struggle, to relate the story from the indigenous perspective, i.e. from the angle of the politically disenfranchised. Disabled and paralyzed, Sabri finds a way to resist, fight back and overcome his impairment. An integral part of Sabri's persistence to write his private history in tandem with that of the Palestinian Intifadas (Palestinian uprisings) and the recurrent lethal Israeli military assaults on Gaza is to regain the sense of wholeness as it is the ultimate vehicle to exercise agency over his life narrative. In Sabri's case, identity transformation and documenting several aspects of the Palestinian struggle are interconnected. By writing down and documenting the history of Gaza, Sabri tries to re-envision and re-configure his own identity. As a matter of fact, re-imagining the past is a self-sustaining technique in Sabri's case since this process reinforces his hopes for a better future that is unhindered by the Israeli occupation, crippling blockade and recurrent military raids on Gaza.

Sabri documents the history of Gaza in an attempt to connect the public history with the private one and to re-envision his own identity. In a correspondence with his brother, Sabri declares that "you will find this research to be of great interest and importance, not just to my book but also in terms of [. . .] our own particular history as a family" (Dabbagh 2011: 121, Italics in original). The interconnection between the private and the public is a re-imagination of the hope for a better life and future. This re-imagining is self-sustaining, not just for Sabri who presents the most complex example of how the Israeli occupation of Palestine further marginalizes disabled Palestinians, but it also reinforces the 
hopes of his fellow Palestinians who share a common situation under the Israeli occupation, the crippling blockade and recurrent military attacks on Gaza. Sabri's accounts and Dabbagh's fictional work restore in innovative ways the hidden history of Palestine.

In this context, "[t]he process of writing," as Alice Hall stipulates in Literature and Disability, "is itself associated with overcoming obstacles, disrupting stereotypes of dependency and vulnerability; it becomes an act of defiant and triumphant self-inscription" (2012: 131). Seen from this perspective, writing is an empowering practice, an essential platform for interpersonal expression for people with disabilities. It is their opportunity to be actively involved in the socio-political events of the modern world. Within the context of the Israeli occupation of Palestine, writing is a national practice to defy and reverse the power of the occupier. In Sabri's case, writing about and for a great cause enables him to endure the physical obstacles that restrict his movement. In writing, Sabri transcends his disability and the wheelchair to which he is bound. The process of writing immunizes him against falling vulnerable to a state of inactivity, despondency and self-censure.

Sabri becomes a father figure, researcher and human rights activist. In his writings, Sabri lucidly articulates his views on intersecting private and public issues. The protagonist embarks on the study of the uprising. The novelist shows how the private life of her protagonist Sabri intermingles with the public sphere in a kind of reciprocal relationship whereby both individuals and their surroundings affect each other. Specifically, Dabbagh highlights the influence of the political and national circumstances on the life of Sabri. In chapters six and twelve in the novel, i.e. chapters concerned with Sabri, the narrative fluctuates between Sabri's private life in the past and the public Palestinian life represented by the present conflict. This transition is meant to show Sabri's transformation from a recluse into an activist. In other words, the narrative technique that Dabbagh employs in these two chapters reflects Sabri's involvement in the Palestinian public life. To illustrate, at the start of chapter six Sabri sits behind his desk and writes about the merchants' strike in Ramallah during the Palestinian Uprising (Intifada) of 1988. $\mathrm{He}$ barely finishes his first paragraph before he falls in a reverie about his first days with his wife, Lana. The daydream continues till the end of the chapter when Sabri "conclude[s] the paragraph [...] and read[s] through it with his editing pencil poised above it" (Dabbagh 2011: 44). Here, the private life of Sabri is sandwiched between the two passages he writes about a grave national question. Another form of intersection that shows how the history of his family is interwoven with that of the nation is evident in Sabri's writing about "the roots of the divide", in which he either talks about the divorce of his father and mother or the fact that Palestinians are divided into conflicting factions. Such a glide between individual questions and national concerns, as disability studies' critic Clare Barker argues, is typical of how disability functions in the postcolonial novel (2010: 100). In other words, the public sphere impinges on the private sphere and continually permeates it. 
Chronicling crucial episodes of the first and second Intifadas and meticulously investigating the current Palestinian situation are forms of resistance that Sabri is actively involved in. In fact, the history of the uprising reveals for Sabri the internal and external betrayals in which "our Arab brothers assisted" (2011: 103). While following his narrative, Sabri records the "missed opportunities of having the Palestinian land back" and he slams "the corrupt leadership" that ruined everything. What he aims at exposing is the conspiracy on Palestine. Plainly, it was "one long history of betrayal. They [Israelis] screw us; we betray ourselves" (ibid: 104). During the nights of Israeli attacks on Gaza, Sabri keeps his "notepad", "binoculars" and two sharpened pencils by the desk to write down "eyewitness accounts" of Israeli atrocities against civilians (ibid: 36). Sabri dedicates himself to raising this national issue to an international level by appropriating the English language as a tool of expression.

Sabri's identity transformation is also reflected in the way he reacts to other local social issues and familial matters. For instance, Sabri adopts a young boy named Wael. Becoming both a spiritual father and a care giver marks an important shift in Sabri's identity transformation after impairment. Just as Sabri sets himself the mission of raising the national cause of Gaza to an international level, he takes it upon himself to bring up the boy of Abu Omar, his treacherous neighbor. Following Sabri's lead, Wael pursues a similar path to Sabri's revolutionary road. As Rashid states, the boy is "so principled and so dedicated to the cause" (ibid 254) that he refuses to leave the Strip. Wael is somehow a replacement to Sabri's son whom he lost in the Israeli targeted bombing. With Wael, Sabri becomes able to retrieve feelings of fatherhood, home and family once again. Moreover, Sabri extends his protective hand to shield refugees living in neighboring tents. In these circumstances, he offers his apartment to house a considerable number of displaced refugees regularly. With his mother's help, Sabri arranges a "rota" to organize receiving refugees in two-week shifts for each family (ibid: 123). In doing so, Sabri devotes his life to those in need of his help.

At the family level, his benevolent hand stretches to his twin siblings Rashid and Iman. If Iman needs a consultation in matters of joining the Women's Committee and in case she wants to decipher the current political situation, Sabri would always be the one to help. When Rashid seeks to escape from Gaza's disabling environment to England, Sabri "reminds him that he could never relax, never be part of anything or anywhere unless it was part of a push for a change" (ibid: 120). With his wise comments, Sabri in his wheelchair is the catalyst for Rashid's change. By that, he fulfills a fatherly, caring and protective role. Sabri encourages his young bother to conduct new research in England as he is fortunate enough to get out of Gaza and continue exposing the inhumane project of the apartheid state of Israel. By entrusting Rashid with this honorable mission, Sabri builds up a new generation that ensures the continuation of Palestinian resistance in order to make the future of the Palestinian people possible. 


\section{Conclusion}

It is of great interest that disability studies provide a fresh lens to understand the inner worlds of characters with disabilities in literary texts. What this study proves is that disability, specifically physical disability, stimulates a transformation in an individual's identity. Disability studies rise to confront the orthodox perception of disability as an "individual impairment that requires medical treatment" (Barnes and Mercer 2001: 515). In contrast with the medical point of view, disability theory argues that disability is the result of social, economic and environmental challenges. In Out of It, Selma Dabbagh problematizes the concepts of identity, disability and loss by portraying her protagonist's resilient spirit. This study has examined how disability instigates a change in the main character's identity and how this transformation is quite positive and fruitful. Dabbagh, this study maintains, deliberately employs disability in her novel for thematic, aesthetic and ethical purposes in a way to criticize the socio-economic, political and cultural environment.

In their book Cultural Locations of Disability, Snyder and Mitchell call for a shift towards the localized settings of each culture and how that affects the overall identification and meaning of disability itself. In colonial / postcolonial contexts this practically means studying disability vis-à-vis issues of political power, hegemony and global economy along with local socio-cultural dynamics. Seen from the above perspectives, one may view how "representations and narratives of postcolonial disability reorient, in a fundamental fashion, our understanding of such disability" (Barker and Murray 2010: 220). The intersection between postcolonial theory and disability studies provide rich diversities that destabilize the fixed paths to individualism, independency and identity. In short, both approaches seek to empower the historically silenced and to give them voice so that they become able to narrate their own experience. Understanding Sabri's identity transformation requires that we "read" his disability within the localized settings of a nation under occupation and siege.

In telling the story of the Mujahed family, Dabbagh narrates Palestinian stories of crippling conditions under unjust siege, recurrent Israeli atrocities against Palestinians and pointless factional conflicts. Depicting the everyday life in Gaza through the lens of the wheelchair-bound Sabri and his young twin siblings, Rashid and Iman, reflects the diverse outlooks and considerations of the national cause. The sense of a collective identity that Palestinians share surpasses any type of demeaning gaze towards those who, as a result of recurrent Israeli military attacks, become physically or mentally different. People who suffer in Gaza have a kind of solidarity that defies disparity. Resistance is a basic marker of the collective identity that unifies all Palestinian parties. The particularity of the Palestinian situation presents Sabri as a source of pride and a role model whose presence adds richness to the lives of others.

In all respects, disability positively influences Sabri's identity transformation in Out of It. Sabri's disability paves the way for exploring the self from a new perspective. As a result of suffering from disability and disabling conditions, Sabri's interaction with people around him, who are metaphorically 
handicapped and crippled due to the strangling blockade on Gaza, is seamless and smooth. Sabri becomes socially involved and helps the unprivileged Palestinians. Had he not been beleaguered with such a traumatic incident, Sabri would probably not have explored his exquisite potentials to be part of a great cause at a grassroots level. Sabri forms an integral part of the collective identity of the Palestinian national fabric and body politic. His identity is not bound to an individualistic and self-reflective mode as perceived in other disability examples in the context of the First World. As Sabri's case shows, presenting disability within the context of Israeli occupation and the siege on Gaza involves investigating complex and intertwining cultural, environmental and socio-political relationships. Hence, Sabri's disability is a site over which socio-political, historical and cultural discourses converge.

Nedal Al-Mousa

Arab Open University, Jordan

ORCID Number: 0000-0003-0078-0580

Email: n_almosa@aou.edu.jo

Laura Bashiti

The World Islamic Sciences and Education University, Jordan

Email: laura_bashete@hotmail.com

\section{References}

Awad, Yousef. (2018). Fiction in Contrast with History? Faith Resilience and the War on Terror in Aboulela's The Kindness of Enemies. Vol. 18. 53-73. International Journal of Arabic-English Studies

Barker, Clare (2016). "Disability and the Postcolonial Novel." In The Cambridge Companion: The Postcolonial Novel, edited by Ato Quayson, 99-115. New York: Cambridge UP.

Barker, Clare and Stuart Murray. (2010). 'Disabling postcolonialism: global disability cultures and democratic riticism '. Journal of Literary \& Cultural Disability Studies 4 (3): 219-236. doi.org/10.3828/jlcds.2010.20.

Barnes, Colin and Geoff Mercer. (2001). "Disability Culture: Assimilation or Inclusion?" In Handbook of Disability Studies, edited by Gary L. Albrecht, Katherine Seelman and Michael, 515-534. Thousand Oaks, CA, London \& New Delhi: SAGE.

Chomsky, Noam. (2015). "Nightmare in Gaza." In On Palestine, edited by Noam Chomsky and Ilan Pappé, 155-165. London: Penguin.

Dabbagh, Selma. (2011). Out of It. London: Bloomsbury.

Davidson, Michael. (2008). Concerto for the Left Hand: Disability and the Defamiliar Body. Ann Arbor, MI: University of Michigan Press.

Davis, Lennard. (2013). "Normality, Power, and Culture." In Disability Studies Reader, edited by Lennard Davis, 15-28. London and New York: Routledge. 
Gibson, Barbara E. (2006). 'Connectivity and transgressing the autonomous Body'. Journal of Medical Humanities 27(3): 187-196. doi.org/10.1007/s10912-006-9017-6.

Goodley, Dan. (2010). Disability Studies: An Interdisciplinary Introduction. London: Sage.

Hall, Alice. (2015). Literature and Disability. London \& New York: Routledge.

Hall, Alice. (2012). Disability and Modern Fiction: Faulkner, Morrison, Coetzee and the Nobel Prize for Literature. New York: Palgrave Macmillan.

Hall, Stuart. (1994). "Cultural Identity and Diaspora." In Colonial Discourses and Postcolonial Theory: A Reader, edited by Patrick Williams and Laura Chrisman, 222-237. New York: Columbia UP.

Hamdar, Abir. (2014). The Female Suffering Body: Illness and Disability in Modern Arabic Literature. Syracuse, NY: Syracuse UP.

Hunt, Paul, ed. (1966). Stigma: The Experience of Disability. London: Geoffrey Chapman.

Mitchell, David T. and Sharon L. Snyder. (2014). Narrative Prosthesis: Disability and the Dependencies of Discourse. Ann Arbor, MI: The University of Michigan Press.

Moore, Lindsey. (2015). "A conversation with Selma Dabbagh'. Journal of Postcolonial Writing 51(3): 324-339. doi: 10.1080/17449855.2014.954755.

Murugami, Margaret W. (2009). 'Disability and identity '. Disability Studies Quarterly 29(4). http://dsq-sds.org/article/view/979/1173.

Pappé, Ilan. (2015). “A Brief History of Israel's Incremental Genocide.” In On Palestine, edited by Noam Chomsky and Ilan Pappé, 147-154. London: Penguin.

O’Toole, Megan. (2015). "Q\&A: Wheelchairs for Gaza." Al Jazeera, April 5. http://www.aljazeera.com/news/2015/04/qa-wheelchairs-gaza150404123217406.html

Quayson, Ato. (2012). Aesthetic Nervousness: Disability and the Crisis of Representation. New York: Columbia UP.

Schalk, Sami. (2016). 'Reevaluating the supercrip '. Journal of Literary \& Cultural Disability Studies $10 \quad$ (1): 71-86. https://doi.org/10.3828/jlcds.2016.5.

Snyder, Sharon L. and David T. Mitchell. (2006). Cultural Locations of Disability. Chicago \& London: University of Chicago Press.

UNHRC. (2015). "Report of the Independent Commission of Inquiry on the 2014 Gaza Conflict -- A/HRC/29/52." United Nations Human Rights Council, June 24.

http://www.ohchr.org/EN/HRBodies/HRC/CoIGazaConflict/Pages/ReportC oIGaza.aspx\#report.

Westall, Sylvia. (2014). "After Month of War, Gaza's Disabled Face Shortages, Isolation." Reuters, August 10. http://www.reuters.com/article/usmideast-gaza-disabled-idUSKBN0GA09I20140810. 